\title{
Investigation on acceptable reverberation time at various frequency bands in halls that
} present amplified music

\section{Adelman-Larsen, Niels Werner; Jeong, Cheol-Ho; Støfringsdal, Bård}

\section{Published in:}

Applied Acoustics

Link to article, DOI:

10.1016/j.apacoust.2017.07.005

Publication date:

2018

Document Version

Peer reviewed version

Link back to DTU Orbit

Citation (APA):

Adelman-Larsen, N. W., Jeong, C-H., \& Støfringsdal, B. (2018). Investigation on acceptable reverberation time at various frequency bands in halls that present amplified music. Applied Acoustics, 129, 104-107. https://doi.org/10.1016/j.apacoust.2017.07.005

\section{General rights}

Copyright and moral rights for the publications made accessible in the public portal are retained by the authors and/or other copyright owners and it is a condition of accessing publications that users recognise and abide by the legal requirements associated with these rights.

- Users may download and print one copy of any publication from the public portal for the purpose of private study or research.

- You may not further distribute the material or use it for any profit-making activity or commercial gain

- You may freely distribute the URL identifying the publication in the public portal 
7

8

9

10

An article submitted to Applied Acoustics

Investigation on acceptable reverberation time at various frequency bands in halls that present reinforced music

Short title: Reverberation times for amplified music

\author{
Niels Werner Adelman-Larsen ${ }^{\text {a) }}$ \\ Flex Acoustics, Ny Carlsbergvej 27, 1760 Copenhagen V, Denmark
}

(1)

\title{
Cheol-Ho Jeong
}

Acoustic Technology, Technical University of Denmark, 2800 Kongens Lyngby, Denmark

chj@elektro.dtu.dk

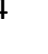

\section{Bård Støfringsdal}

COWI, Hafstadvegen 15, 6800 Førde, Norway

bst@cowi.com 


\section{ABSTRACT}

2 Subjective ratings from 25 professional musicians and sound engineers were obtained to assess two

3 Danish rock venues of similar size and similar low frequency reverberation, but different high frequency

4 reverberation. The musicians judged one hall significantly better than the other, confirming a hypothesis

5 that rock venues can have a longer reverberation time at mid to high frequencies. A fairly long

6 reverberation time in the $63 \mathrm{~Hz}$ octave band is found to be acceptable, so the $125 \mathrm{~Hz}$ octave band is

7 probably the single most important band to control for reinforced music.

8 (C) 2017 Applied Acoustics

9

10 Keywords: reinforced music, reverberation time, bass clarity, concert hall rating, amplified music

12 This research did not receive any specific grant from funding agencies in the public, commercial, or not13 for-profit sectors. 
1

2

3 Part of the perceived sound quality at any given indoor, reinforced concert stems from the quality, 4 extent, and tuning of the sound system, whereas another part stems from the acoustics of the hall. There

5 has been limited scientific research effort published with the attempt to find recommendations for 6 acoustics for amplified music concerts. A paper examined 20 Danish pop and rock venues, of which the 7 acoustic conditions were measured and rated by musicians and sound engineers for halls of volume 8 from approximately $1000 \mathrm{~m}^{3}$ to $7000 \mathrm{~m}^{3}$ [1]. From the study, the recommended reverberation time, 9 expressed as $T_{30(63-2 \mathrm{k})}$ for a given venue size, was suggested on the basis of sound engineers' and 10

\section{Introduction}

musicians' preference as one group. It was also found that the group of sound engineers in that particular survey preferred more dampened acoustics than the musicians, giving preference to the hall that had lowest reverberation time in the study.

It was further substantiated that what separates the best from the not so well liked venues is a shorter $T_{30}$ in the $63 \mathrm{~Hz}, 125 \mathrm{~Hz}$ and $250 \mathrm{~Hz}$ octave bands. This finding is important, but actually not surprising, since bass levels are amplified to very high levels at pop and rock concerts, typically app. $100 \mathrm{~dB}(\mathrm{~A})$ $[2,9]$. One paper [8] examined the sound pressure levels at various frequency bands for a large sample of popular recordings and found that the loudest level is found in the $125 \mathrm{~Hz}$ octave band. The level in the $125 \mathrm{~Hz}$ band was found to be about $5 \mathrm{~dB}(\mathrm{~A})$ louder than the $63 \mathrm{~Hz}$ band. Similarly in [2] for actual live pop/rock concerts, it was found that the sound pressure level in the $125 \mathrm{~Hz}$ octave band was about $4 \mathrm{~dB}(\mathrm{~A})$ louder than in the $63 \mathrm{~Hz}$ band while an other survey [9] found the $125 \mathrm{~Hz}$ level to be in average $9 \mathrm{~dB}(\mathrm{~A})$ louder than the $63 \mathrm{~Hz}$ level. Many instruments in a pop/rock band, including male vocal, play notes within the $125 \mathrm{~Hz}$ octave band with often quite syncopated rhythms. One sound is 
1 thus difficult to differentiate from another if the reverberation in this band is too long. At loud sound

2 levels, upward masking from this reverberant bass sound is quite broad [3].

3 This study first and foremost investigates whether it is plausible that the value of $T_{30}$ in certain octave

4 bands can differ from the suggested frequency independent values set forth in Ref. [1], with a particular

$5 \quad$ interest in the $63 \mathrm{~Hz}$ band and the mid to high frequency range. This idea has already been postulated in

6 a conference article [4]. Hence this present study is a continuation of the research carried out in [1] and

7 [4], and the same methodology that was used in [1], collecting the subjective ratings on a 7-scale, is 8 applied here.

\section{Hypotheses}

This article seeks to substantiate or reject the hypotheses presented below. All of these have previously been proposed in Refs. [2] and [4].

1) Acousticians normally measure empty halls, whereas sound engineers and musicians experience occupied conditions. Due to a 4-6 times higher absorption coefficient by audience, seated or standing, at higher frequencies than at low frequencies [1], it is possible that a higher $T_{30}$ at higher frequencies in the empty hall can be accepted. This leads to a more even $T_{30}$ over frequency in the occupied hall.

2) Due to the higher directivity of loudspeakers at higher frequencies compared to low, it is further possible that an increasing $T_{30}$ with increasing frequencies might be acceptable or even desirable. This hypothesis was exemplified in Ref. [5] from the perspective of the critical distance, and its dependency of the directivity $Q$. The equation for critical distance $r, c r$, as 
stated in [10], is shown in (1) below, where $V$ is the volume of the hall, $T$, the reverberation time, and $\alpha^{\prime}$ is the average absorption coefficient of the room.

$$
r, c r=\sqrt{\frac{Q V}{100 \pi T\left(1-\alpha^{\prime}\right)}}
$$

Since $Q$ can easily be a factor of 5 higher at mid-high frequencies compared to low, for the critical distance to be constant at various frequencies, the reverberation time would have to be higher at mid-high frequencies compared to low. Evidently, such a space with increased $T_{30}$ at higher frequencies will sound more live and the audience will be louder. It will also be easier for the musician to express dynamics [11]. In smaller clubs where the musicians' own instruments and open monitors, and not the PA sound system, is the main source of amplification, this broader tolerance of $T_{30}$ does not apply.

3) Due to the more densely spaced equal-loudness contours in the $63 \mathrm{~Hz}$ octave band compared to the $125 \mathrm{~Hz}$ band [3], it is possible that reverberation in the $63 \mathrm{~Hz}$ band can be longer and still acceptable. Perceptually, reverberation in the $63 \mathrm{~Hz}$ band disappears faster than in the $125 \mathrm{~Hz}$ band.

4) A main conclusion in Ref. [2] is that probably the most important octave band to control for pop and rock concerts is the $125 \mathrm{~Hz}$ band. Sound in this band emerges omni-directionally from the speakers, thereby reaching many surfaces in the room, adding up reverberation. It is amplified to high levels, and therefore has a significant spectral masking effect, especially towards higher frequencies. The human ear is less sensitive in the $63 \mathrm{~Hz}$ band than in the $125 \mathrm{~Hz}$ band [3]. Sound in the $250 \mathrm{~Hz}$ band is more directive and is better absorbed by the audience [2]. Further, according to [2] and [8], sound levels are louder in the $125 \mathrm{~Hz}$ octave band than in the $63 \mathrm{~Hz}$ band, wherefore reverberation in the $125 \mathrm{~Hz}$ band will mask more the in $63 \mathrm{~Hz}$ band. 
1 The main aim of this article is to find answers to the hypotheses one and two, and loosely discuss the

2 results in relation to the hypotheses three and four.

3

4 3. Method

5

625 musicians and sound engineers rated two Danish halls of similar volume: Skråen and Magasinet.

7 The two halls have very similar low frequency $T_{30}$, while $T_{30}$ at higher frequencies is significantly

8 higher in Magasinet than in Skråen, as shown in Figure 1, measured in empty state.

9

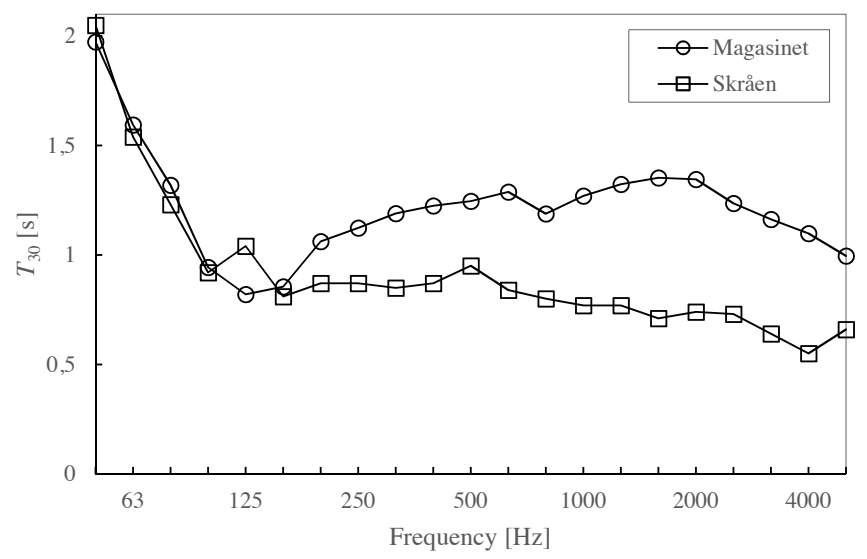

10

11 Figure 1. $T_{30}$ of the two venues, Magasinet and Skråen, in the empty condition.

12

\subsection{The two halls}

14

15 To the best knowledge of the authors, there is only one hall in Denmark, Magasinet of $2700 \mathrm{~m}^{3}$, which 16 has a controlled $T_{30}$ in the $125 \mathrm{~Hz}$ octave band and a relatively high $T_{30}$ at mid- and high frequencies. In 17 this hall, reverberation is controlled exclusively by means of membrane absorption, placed in the entire 
1 ceiling area and on a big wall area behind the stage. The hall has little high frequency absorption,

2 limited to scarcely distributed textiles on stage and upholstered chairs on the balcony level.

3 The other venue, Skråen of $4000 \mathrm{~m}^{3}$, has porous absorption in the entire ceiling and on the back wall,

4 by means of suspended wooden fiber elements. Magasinet was renovated in 2008, while Skråen moved 5 to new premises in the same year.

6

\subsection{Subjective survey}

8 Ref. [1].

The administrators of the two halls informed the authors which bands had regularly performed in their venues within the last 5-6 years. A link to an on-line questionnaire was e-mailed to the relevant musicians and sound engineers it was possible to contact. Of the 25 people who answered the survey, 11 were sound engineers and 14 were musicians. The choice to make the questionnaire anonymous was made so as to render as much freedom to the test persons as possible. By coincidence, none of the musicians who participated in the previous survey [1] were involved in this present survey. It is uncertain whether any of the eleven sound engineers had also participated in the survey presented in

The on-line survey started with a group of general questions: what monitoring do you use?, how important is the acoustics in the venue for you? (rating 1: not at all/rating 7: very important), do you sometimes chose not to play certain venues on the account of the acoustics? These questions could not be left unanswered in the survey. Then, each of the two halls could be rated on four different parameters on a seven-scale: Clarity bass (rating 1: muddy/ rating 7: clear), Clarity mid/treble (rating 1: muddy/ rating 7: clear), Reverberation mid/treble (rating 1: too dead/rating 7: too lively - rating 4: optimal), and General rating (rating 1: very poor, rating 4: reasonable, rating 7: excellent). At the end 
1 of the questionnaire, the test person was asked to write whatever he/she deemed of importance 2 regarding acoustics for amplified music.

3 
1

2

3

4

514 musicians answered the questionnaire: two lead singers, five guitarists, one keyboard player, three

6 bass players, and three drummers. In response to the question: "how important is the acoustics in the

7 venue for you?", the average of eleven sound engineers' ratings was 6.6 out of 7 , while the average of

814 musicians' answers was 5.9. It is unknown how many musicians got the questionnaire and chose not

9 to answer it. It cannot be ruled out that the musicians who do not deem acoustics so important are not

\section{Results and discussion}

\subsection{First part of the questionnaire} eager to answer this type of questionnaire. Of the 14 musicians, seven use in-ear monitors. Six of those who use in-ear monitoring also use open monitor speakers. Both lead singers reported that they sometimes chose not to attend venues on account of the acoustics. Only three musicians and four sound engineers answered positively to this question. It is plausible that the lead singer often takes such decisions when booking the tour. On the question regarding to what extent in-ear monitors can help mitigate the possible bad effects of a hall's acoustics, the musicians' average answer was 4.6 out of 7 , whereas the sound engineers' average response to this question was 5.5. These results are in agreement with the findings in Ref. [1].

\subsection{Analysis of the ratings}

In order to find evidence for the hypotheses mentioned, a linear mixed model and Analysis of Variance (ANOVA) are attempted to explain the subjective ratings $S_{i j k}$ in Table 1: 
$1 \quad S_{i j k}=A+\alpha_{i}+B j+C k+D \delta_{j k}+\varepsilon_{i j k}$

2 where $i$ is the subject, $j$ is the concert hall ( $j=0$ for Magasinet, and $j=1$ for Skråen), and $k$ is the 3 occupation of the respondent ( $k=0$ for musicians and $k=1$ for sound engineer) $[6,7]$

5 The fixed effects are written with upper case Latin characters (A, B, C and D) and the random effects 6 are written with Greek characters (here only $\alpha_{i}$ ). $\delta_{j k}$ is the Kronecker delta function. The random effect

7 is regarded as a normally distributed stochastic variable with zero mean and standard deviation, $\sigma_{\alpha}$. The 8 residual or unexplained variation, $\varepsilon_{i j k}$, is also assumed to be normally distributed with zero mean. The 9 choice of the mixed model is based on the assumption that a considerable amount of the variance in the observations is dependent on inter-subject differences, so the subject is regarded as a random effect. However, this inter-subject effect is found to be much smaller than the residual term, so the final model 12 is constructed without the $\alpha_{i}$ term. Significant differences are found only for the general rating (GR) and the bass clarity $(B C)$, and their final models are found to be

$G R_{i j k}=5.55-1.55 j-1.21 k+1.41 \delta_{j k}+\varepsilon_{i j k}$.

$B C_{i j k}=5.45-1.03 j-1.01 k+0.38 \delta_{j k}+\varepsilon_{i j k}$.

16 From Eq. (2), we can see that the musicians' general rating is averaged to 5.55 for Magasinet $(j=0)$, and sound engineers' rating is 4.0 for Skråen $(j=1)$. Similarly, the bass clarity is 5.45 for Magasinet and 4.42 for Skråen. For these two ratings, the sound engineers' responses are lower than the musicians' by about 1 , on average.

For the general rating, a 2-way ANOVA, which does not take into account the respondents as a random effect, gives a significant variation using the hall (Magasinet or Skråen) as the factor (*significance, 
$1 p=0.044$ ). However, there was no significant variation depending on the occupation (musician or

2 sound engineer) as the factor $(p=0.31)$, or including the interaction between hall and occupation

3 condition $(p=0.12)$. Only using the musicians' responses, an ANOVA analysis shows a $p$-value of

$40.0066(* *$ significance), which indicates that the musicians rated Magasinet significantly better than

5 Skråen in the overall rating. This result supports hypothesis one and two. Both lead-singers have rated

6 Magasinet "7", while rated Skråen "1" and "3". One of them commented that he would recommend

7 future halls to be acoustically similar to Magasinet, supporting hypotheses 3 and 4. More lively mid-

8 high acoustics with more vivacity makes the performer hear the audience better, whereby the

9 communication and the exchange of energy between band and audience are enhanced. This is

10 particularly important for the lead-singer who forms a "bridge" between the band and the audience.

11 Further, the musician can express dynamics easier. Only using the sound engineers' overall rating, the

12 two halls are not significantly different $(p=0.915)$.

13 The bass clarity is found to be significantly different depending on the hall and occupation with $p$ values of 0.025 and 0.031 , respectively. This is surprising since the actual reverberation curves for the $63 \mathrm{~Hz}$ and $125 \mathrm{~Hz}$ regions are almost identical, which may indicate that mid to high frequency reverberation could possibly mask low frequency reverberation.

Significant differences between the two halls for the Clarity mid/treble rating, are not found. It should be noted that once the audience enters a hall like Magasinet, mid/treble reverberation decreases significantly, so that such a venue probably is perceived with a suitable, high degree of clarity in the mid to high frequency domain. 


\begin{tabular}{|c|c|c|c|c|c|c|c|c|}
\hline & \multicolumn{4}{|c|}{ "Magasinet } & \multicolumn{4}{|c|}{ Skråen } \\
\hline & $\begin{array}{l}\text { Clarity } \\
\text { bass }\end{array}$ & $\begin{array}{l}\text { Clarity } \\
\mathrm{mid} / \text { treble }\end{array}$ & $\begin{array}{l}\text { Reverb } \\
\mathrm{mid} / \text { treble }\end{array}$ & $\begin{array}{l}\text { General } \\
\text { rating }\end{array}$ & $\begin{array}{l}\text { Clarity } \\
\text { bass }\end{array}$ & $\begin{array}{l}\text { Clarity } \\
\mathrm{mid} / \text { treble }\end{array}$ & $\begin{array}{l}\text { Reverb } \\
\text { mid/treble }\end{array}$ & $\begin{array}{l}\text { General } \\
\text { rating }\end{array}$ \\
\hline$\overline{\mathrm{SE}}$ & - & - & - & - & - & - & - & 6 \\
\hline SE & 5 & 3 & 6 & 3 & 3 & 1 & 6 & 2 \\
\hline SE & 3 & 5 & 4 & 4 & 3 & 4 & 4 & 4 \\
\hline SE & 3 & 5 & 5 & 4 & 5 & 4 & 4 & 5 \\
\hline SE & 5 & 3 & 3 & 5 & 4 & 6 & 4 & 7 \\
\hline SE & 7 & 7 & 4 & 7 & 1 & 5 & 4 & 1 \\
\hline SE & 6 & 5 & 3 & 5 & 4 & 4 & 5 & 3 \\
\hline SE & 3 & 5 & 6 & 3 & 4 & 4 & 5 & 4 \\
\hline SE & - & - & - & - & 4 & 5 & 5 & - \\
\hline SE & 3 & 3 & 5 & 3 & 6 & 6 & 4 & 6 \\
\hline SE & 5 & 5 & 5 & 5 & 4 & 4 & 4 & 4 \\
\hline Average & 4.4 & 4.6 & 4.6 & 4.3 & 3.8 & 4.3 & 4.5 & 4.2 \\
\hline Guitar & 6 & 6 & 6 & 6 & 6 & 6 & 6 & 6 \\
\hline Guitar & 5 & 5 & 4 & 6 & 4 & 4 & 3 & 3 \\
\hline Guitar & - & - & - & - & 5 & 5 & 5 & 5 \\
\hline Guitar & 5 & 5 & 5 & 5 & 5 & 5 & 5 & 5 \\
\hline Guitar & 5 & 5 & 4 & 4 & 4 & 4 & 3 & 4 \\
\hline Drums & 5 & 5 & 5 & 5 & 4 & 5 & 5 & - \\
\hline Drums & 5 & 5 & 5 & 5 & 4 & 4 & 4 & 4 \\
\hline Drums & 5 & 6 & - & 5 & 4 & 6 & 4 & 4 \\
\hline Bass \& gtr. & 6 & 6 & 4 & 6 & 6 & 6 & 1 & 2 \\
\hline Bass & - & - & - & - & 4 & - & - & 4 \\
\hline Bass & 5 & 5 & 5 & 5 & 6 & 6 & 6 & 6 \\
\hline Keyboards & - & - & - & - & 5 & 5 & 4 & 5 \\
\hline Vocal & 7 & 7 & 7 & 7 & 2 & 2 & 1 & 1 \\
\hline Vocal & 6 & 6 & 4 & 7 & 3 & 3 & 2 & 3 \\
\hline Average & 5.5 & 5.5 & 4.9 & 5.6 & 4.4 & 4.7 & 3.8 & 4.0 \\
\hline
\end{tabular}

2 Table 1. Individual ratings of the two halls. SE means a sound engineer.

3

\section{5. Conclusion}

5 Among two pop/rock music venues with a similar $T_{30}$ at low frequencies yet quite different $T_{30}$ at high

6 frequencies, Magasinet with the higher $T_{30}$ at mid-high frequency, has been rated significantly better

7 among the musicians than Skråen. This is an indication that mid-high frequency reverberation can be

8 longer than the reverberation in the low frequency bands in the empty hall. The fact that the bass clarity

9 at Magasinet is rated decent, despite a very high $T_{30}$ in the $63 \mathrm{~Hz}$ band, could indicate a high tolerance

10 toward a high $T_{30}$ in the $63 \mathrm{~Hz}$ band as long as $T_{30}$ in the $125 \mathrm{~Hz}$ band is controlled. Therefore, it is 
1 likely that the $125 \mathrm{~Hz}$ octave band is the most important frequency band to control for reinforced music.

2 Furthermore, the difference in the rating of the bass clarity between the two halls, despite their similar

$3 \quad T_{30}$ in the 63 and $125 \mathrm{~Hz}$ bands, indicates that long reverberation at mid-high frequencies can mask 4 excessive low frequency reverberation. 
1

2

3

4

5

6

7

8

9

10

\section{References}

(1)

[1] N.W. Adelman-Larsen, E.R. Thompson, A.C. Gade. Suitable reverberation times for halls for rock and pop music. J. Acoust. Soc. Am. 2010; 127:247-255.

[2] N. W. Adelman-Larsen. Rock and pop venues, acoustic and architectural design. Heidelberg: Springer Verlag; 2014, p. 39.

[3] E. Zwicker, H. Fastl. Psychoacoustics - Facts and Models. 2nd ed. New York: Springer Verlag; 1999, p. 64-65, 168-169, 204.

[4] N.W. Adelman-Larsen, E.R. Thompson, J.J. Dammerud. On a variable broadband absorption product and acceptable tolerances of reverberation times in halls for amplified music. Proceedings of Meetings on Acoustics. 2012;14(1):015002.

[5] B. Støfringsdal. Desired room acoustical response for amplified music. International Symposium on Room Acoustics; 2013 June 9-11; Toronto, Canada; 2013.

[6] D. Hedeker, Generalized linear mixed models - In: Encyclopedia of Statistics in Behavioral Science. 2nd ed. B. Everitt, D. Howell (eds.). New York: John Wiley and Sons, 2005.

[7] J. Brunskog, H. D. Hwang, C.-H. Jeong. Subjective response to foot-fall noise, including localization of the source position. Acta Acustica United with Acustica. 2011; 97:904-908.

[8] P. Pestana et al. Spectral characteristics of popular commercial recordings $1950-2010$. AES, $135^{\text {th }}$ convention 2013, New York, Convention paper 8960.

[9] JET Griffiths. A survey of sound levels at pop concerts. Health \& Safety Executive Report No. 35/1991. Travers Morgan Environment, East Grinstead, West Sussex.

[10] A. C. Gade: Tentative lecture notes for Course 31240, chapters 7 and 8, Technical University of Denmark, April 2003. 
1 [11] J. Pätynen et al., Concert halls with strong lateral reflections enhance musical dynamics,

2 proceedings of the national academy of sciences of the United States of America, 2014.

3

4

5

6

7

8

9

10

11

12

13

14

15

16

17

18

19

20

21

22

23 


\section{Figure captions}

2 Figure 1. $T_{30}$ of the two venues, Magasinet and Skråen, in the empty condition.

3 Table captions

4 Table 1. Individual ratings of the two halls. SE means a sound engineer.

5 